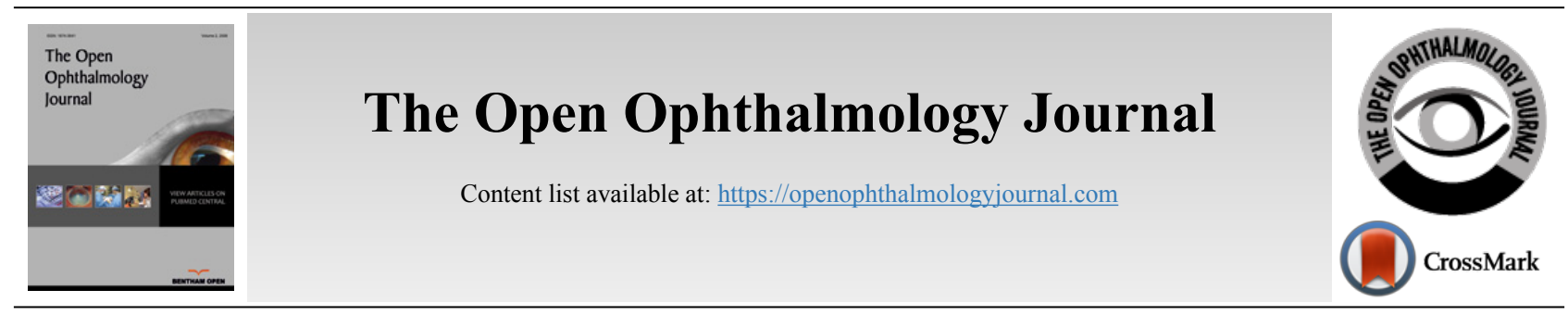

RESEARCH ARTICLE

\title{
Femtosecond Laser-assisted Lens Surgery with Low-energy Pulse versus Conventional Phacoemulsification for Presbyopia Correction: An Intraindividual Study
}

Ramiro M. P. C. Salgado ${ }^{1, *}$, Paulo F. A. A. S. Torres ${ }^{2}$ and António A. P. Marinho ${ }^{3}$

${ }^{I}$ Departamento de Oftalmologia do Hospital da Arrábida. Hospital de Santo António, Centro Hospitalar e Universitário do Porto, Porto, Portugal ${ }^{2}$ Departamento de Oftalmologia do Hospital da Prelada. Universidade do Porto, Porto, Portugal

${ }^{3}$ Departamento de Oftalmologia do Hospital da Arrábida. Universidade do Porto, Porto, Portugal

\begin{abstract}
:
Background:

Lens surgery with multifocal IOL implantation for presbyopia correction is performed by femtosecond laser-assisted lens surgery or conventional phacoemulsification.

Objective:

To compare the clinical results of femtosecond laser-assisted with low-energy pulse conventional phacoemulsification lens surgery for presbyopia correction intraindividually.

Methods:

Charts from patients who underwent Refractive Lens Exchange (RLE) for presbyopia correction in a single center, with Femtosecond LaserAssisted Lens Surgery (FLALS) in one eye and Conventional Phacoemulsification (CP) in the other, were retrospectively reviewed. All eyes had the same multifocal Intraocular Lens (IOL) implanted. The clinical outcomes and the results of the level of satisfaction questionnaire were compared between the two groups according to the technique employed (FLALS vs. CP) for a period of up to four years. Stability, efficacy and safety indices were also assessed.

Results:

This study comprised a total of 56 eyes of 28 patients randomly assigned FLALS in one eye and CP in the other. No statistically significant difference was observed between the two techniques regarding postoperative visual acuities, duration of surgical procedure, efficacy or safety indexes $(\mathrm{p}>0.05)$. Refraction was stable in all FLALS eyes, whereas a change occurred in 2 eyes (7.1\%) operated with CP upon 6 months postoperatively, but without statistical significance $(\mathrm{p}>0.05)$. Satisfaction was slightly better with FLALS but not statistically significant $(\mathrm{p}=0.134)$. No immediate myosis or other adverse events after the femtosecond laser were registered.

Conclusion:

The parameters assessed showed no significant differences between the two techniques, in spite of a difference of refraction stability upon 6 months postoperatively.
\end{abstract}

Keywords: Femtosecond, Presbyopia, Multifocal IOL, Phacoemulsification, FLACS, Intraindividual, Low-energy pulse.

\begin{tabular}{|l|l|l|l|}
\hline Article History & Received: June 26, 2020 & Revised: November 15, 2020 & Accepted: December 30, 2020
\end{tabular}

\section{INTRODUCTION}

Presently, presbyopia surgical correction is mostly addressed by Refractive Lens Exchange (RLE) with multifocal IOLs

\footnotetext{
* Address correspondence to this author at Departamento de Oftalmologia do Hospital da Arrábida, Praceta Henrique Moreira 150, 4400-346 Vila Nova de Gaia, Portugal; Tel: 00351915677244; Fax: 00351224003046;

E-mail: rsalgadoft2@gmail.com
}

implantation. The quality of visual performance after a multifocal IOL implantation is largely determined by common aspects such as decreased contrast sensitivity and photic phenomena [1], which are dependent on the IOL design, residual refractive errors, wavefront abnormalities, and IOL tilt and decentration [2]. Femtosecond Laser-assisted Cataract Surgery (FLACS) has been implemented since 2009 (Nagy et al.) [3]. This technology relies on the use of ultrashort pulses 
(in the femtosecond range, i.e., $10^{-15} \mathrm{~s}$ ), its use being advocated in several steps of modern cataract surgery. Femtosecond laser technology enables a higher accuracy level of centration, circularity and adjustability in capsulotomy, when compared to Conventional Phacoemulsification (CP), besides producing customised multiplanar self-sealing corneal incisions, arcuate keratotomy and lens nucleus fragmentation [4 - 6]. Regarding capsulotomy, more accurate centration and more precise shaping and sizing of capsulotomy are associated with a reduction in the incidence of IOL movement, tilt, and decentration, consequently improving refractive stability and predictability $[7,8]$. Decentered or tilted IOLs have been associated with an increase in Higher-Order Aberrations (HOAs) [9 - 11]. A considerable amount of literature comparing the clinical outcomes of femtosecond laser-assisted cataract surgery versus conventional phacoemulsification has been produced, mostly involving toric and/or monofocal IOLs implantation. Few studies have been published comparing FLACS versus $\mathrm{CP}$ accompanied by multifocal IOL implantation [12].

Furthermore, the majority of publications do not differentiate femtosecond lasers on the basis of the pulse pattern, in spite of the physical evidence that devices differ according to the energy level and frequency of the femtosecond pulses, as outlined by Wu et al. [13]. Most devices produce pulses in the order of $\mu \mathrm{J}$ and $\mathrm{KHz}$, in terms of energy and frequency, respectively. To achieve this type of femtosecond emission, the common mechanism employed by the aforementioned group of devices is Chirped Pulse Amplification (CPA), whereas another type of device produces femtosecond pulses of energy and frequency in the order of $\mathrm{nJ}$ and $\mathrm{MHz}$, respectively, through another, non-disclosed mechanism.

The goal of this study was to evaluate and compare the outcomes, including efficacy, safety, stability, quality of vision and adverse events rate, of femtosecond laser-assisted lens (clear or cataractous) surgery (FLALS, or FS) employing a low energy (on the order of $\mathrm{nJ}$ ) and high frequency (in the order of $\mathrm{MHz}$ ) pulse against Conventional Phacoemulsification (CP) for presbyopia correction with a multifocal IOL implantation.

\section{MATERIALS AND METHODS}

\subsection{Study Design}

A retrospective chart review was performed to identify all patients who randomly underwent presbyopic RLE with panoptix panfocal IOL (Alcon Laboratories, Inc.) implantation in both eyes, with conventional phacoemulsification surgery in one eye and femtosecond laser-assisted surgery in the other, between September 1, 2015, and February 1, 2019, at Hospital da Luz Arrabida (HLA). All surgeries were performed at HLA by two comprehensive cataract and refractive attending physicians using the Centurion Vision (Alcon Laboratories, Inc.) phacoemulsification system and the LDV Z8 femtosecond laser platform (Ziemer, Inc.).

\subsection{Inclusion and Exclusion Criteria}

Preoperative corneal astigmatism less than $0.75 \mathrm{D}$, measured with a Placido - dual Scheimpflug tomographer (Ziemer
Ophthalmic systems AG), was required as an inclusion criteria for the study. Patients were excluded from the study if they had previous ocular surgery other than cataract surgery or RLE, corneal astigmatism more than $0.75 \mathrm{D}$, ocular pathology, corneal abnormalities, and an endothelial cell count less than 2000 cells $/ \mathrm{mm}^{2}$.

\subsection{Chart Review and Data Collection}

A total of 28 patients (56 eyes) were identified in the chart retrospective review, following the inclusion and exclusion criteria. The collection was made of demographic and clinical data such as age, sex, date, lens opacity assessment, type of surgery (conventional versus femtosecond laser-assisted), procedure duration, preoperative and postoperative visual acuities and refractive errors, the stability of refraction, adverse events and quality of vision. All charts were reviewed for the preoperative assessment, at the day of surgery, the day after surgery and the postoperative visits scheduled at 1, 3, 6, 12 months and every year thereafter. Biometry, performed using optical interferometer Galilei G6 (Ziemer Ophthalmic systems AG) and every subsidiary examination (such as OCT, corneal topography, specular microscopy, etc.) were conducted by a technician, unaware of the type of surgical technique employed. Visual acuities, uncorrected and corrected, at a distance (UDVA and DCVA) of $6 \mathrm{~m}$, intermediate (UIVA and DCIVA) at $60 \mathrm{~cm}$ and near (UNVA and DCNVA) at $40 \mathrm{~cm}$ were assessed, under the same photopic conditions (85 candelas $/ \mathrm{m}^{2}$ ), with Snellen chart (for distance) and reading Jaeger chart (for near and for intermediate, with conversion to Snellen notation); ultimately, for analyses purposes, a conversion was also performed to LogMAR notation. Participants' manifested refractions were collected (sphere, cylinder and spherical equivalent), with objective refractive errors assessed by an autorefractor (Topcon Co. Ltd.). Stability of refraction was defined as a manifested refraction change of $\leq 0.5 \mathrm{D}$ between last visit and $1 \mathrm{st}$ month visit, giving attention to the expected full recovering from the inflammatory state during the immediate postoperative period, i. e., up to 1 month after surgery. Safety index was defined as the ratio postoperative CDVA/preoperative CDVA (mean value), and efficacy index as the ratio postoperative UCVA/preoperative CDVA (mean value). Accuracy of spherical equivalent (SE) to the intended target (presented as the percentage of eyes within $\pm 0.13 \mathrm{D}$, $\pm 0.50 \mathrm{D}, \pm 1.00$ and $\pm 1.25 \mathrm{D}$ ) was also measured.

Patient reported outcomes were assessed at the 6 months' visit, using a 5-point Likert scale questionnaire regarding the level of overall satisfaction (graded from 1 - very dissatisfied; 2 - dissatisfied; 3 - neither satisfied nor dissatisfied; 4 - satisfied; 5 - very satisfied) [14], whereas the quality of vision was determined by a 4-point likert scale questionnaire comprising the existence of visual disturbance or photic phenomena, graded from 0 (none) to 4 (very high).

Lens transparency was assessed by slit-lamp examination and assigned a grade according to the Lens Opacities Classification System (LOCS) III. Corneal topography and tomography were determined using a Placido - dual Scheimpflug device (Galilei G6). Macular spectral-domain optical coherence tomography was performed with a modular ophthalmic imaging platform (Carl Zeiss). 
The femtosecond laser-assisted lens surgery was performed using a femtosecond laser (LDV Z8, Ziemer, Inc.). Two surgeons (R.S., A.M.) had received training and full accreditation on the device in anticipation of this trial and had performed at least 20 laser applications each before the study began. The femtosecond laser was used to perform capsulotomy, lens fragmentation and corneal incisions, and a phacoemulsification machine was used for further emulsification, irrigation and aspiration of lens material. Due to the portability of the femtosecond device employed (LDV Z8), the surgery was fully performed in sequence (femtosecond laser followed by the phacoemulsification) in the same operating theater, with the patient on the same operating bed. Phacoemulsification was performed using the Active Fluidics ${ }^{\mathrm{TM}}$ torsional phacoemulsification machine (Centurion Vision, Alcon Laboratories, Inc.). All operations were unilateral (one eye at a time) and performed under sedation. Both surgeons followed the same surgical protocol.

Preparation of patients was the same for both groups, i.e. tropicamide $0.28 \mathrm{mg}$ in association with phenylephrine hydrochloride $5.4 \mathrm{mg}$ contained in an ophthalmic insert (Mydriasert), placed in the lower conjunctival sac and oxybuprocaine hydrochloride $4 \mathrm{mg} / \mathrm{l}$ eyedrops before the procedure, with no specific medication for mydriasis prevention required in the femtosecond group. Injection of intracameral cefuroxime (Aprokam) was performed in every patient at the end of each surgery.

All patients were administered prednisolone (Frisolona Forte), ibuprofen (Edolfene) and ofloxacin (Floxedol) eyedrops for 3 weeks postoperatively.

\subsection{Intraocular Lens}

The Acrysof IQ TNFT00 Panoptix panfocal (Alcon Laboratories, Inc.) is a diffractive aspheric hydrophobic acrylic IOL with a blue light-filtering multifocal design. It is a modified L-haptic lens (0-degree angle), with a $13.0 \mathrm{~mm}$ overall diameter, a $6.0 \mathrm{~mm}$ optic, and a refractive index of 1.55 at a wavelength of $550 \mathrm{~nm}$. The optical zone of the IOL is composed of a diffractive structure in the central $4.5 \mathrm{~mm}$ portion consisting of 15 diffractive zones and an outer refractive annulus. The quadrifocal design was modified so as to provide trifocal functionality for the patient at far $(6 \mathrm{~m}), 60$ $\mathrm{cm}(+2.17 \mathrm{D})$, and $40 \mathrm{~cm}(+3.25 \mathrm{D})$ distance [15]. The
Enlighten Optical Technology employed claims an optimization of light distribution as follows: $50 \%$ for far distance with $25 \%$ each for near focus and intermediate focus, with $88.0 \%$ light transmittance to the retina (for a simulated 3.0 mm pupil) $[16,17]$.

\subsection{Statistical Analysis}

Snellen and Jaeger visual acuities were converted to logarithm of the minimum angle of resolution (logMAR) for analysis. Comparisons were based on Student t-test, or nonparametric Mann-Whitney test when the equality of variances was not observed. The efficacy, in terms of UDVA, UIVA and UNVA at 4 weeks and last visit was designated as the primary outcome, with safety, stability, intraoperative and postoperative complications, refraction and patient-reported quality of vision selected as secondary outcomes. The sample size was determined for a significance level of $\alpha=0.05$ and a power of $90 \%$, considering different standardized effects ranging from 0.9 to 1.25 ; the resulting sample size ranged from 15 to 27 subjects in each group.

\section{RESULTS}

\subsection{Preoperative Patient Data}

The mean age of the 20 women $(76.5 \%)$ and 8 men $(23.5 \%)$ was $58.75 \pm 5.941$ years (range 47 to 73 years). Cataract removal was performed in 4 eyes $(7.1 \%)$, whilst clear lens extraction was performed in 52 eyes $(92.9 \%)$. Mean follow-up was $27.59 \pm 10.146$ months (ranging from 8 to 48 months). The mean IOL power was $+24.38 \pm 3.651 \mathrm{D}$ (ranging from 13.5.0 to $33 \mathrm{D})$.

All 28 patients had both eyes operated, with a total of 56 eyes operated. Femtosecond laser-assisted surgery was performed in 28 eyes $(50 \%)$, whereas conventional phacoemulsification was performed in 28 eyes $(50 \%)$.

Table 1 shows the patients' preoperative characteristics by technique group. There was no statistically significant difference between the 2 groups preoperatively. Regarding CDVA, each group had 26 eyes $(92.8 \%)$ with $20 / 30$ or better (Snellen notation), whereas 2 eyes (7.2\%) in each group had CDVA worse than $20 / 30(p>0.50)$. The cases were distributed evenly between the 2 surgeons and between the 2 treatment techniques $(\mathrm{p}=0.987)$ (Table 2$)$.

Table 1. Patient demographic and clinical characteristics.

\begin{tabular}{|c|c|c|c|}
\hline \multirow{3}{*}{ Parameter } & \multicolumn{3}{|c|}{ Monocular } \\
\hline & \multicolumn{2}{|c|}{ Mean value \pm SD } & \multirow{2}{*}{ P value } \\
\hline & FS & $\mathbf{C P}$ & \\
\hline UDVA (logMAR) & $0.36 \pm 0.302$ & $0.36 \pm 0.294$ & 0.986 \\
\hline CDVA (logMAR) & $0.03 \pm 0.080$ & $0.04 \pm 0.077$ & 0.865 \\
\hline Spherical Equivalent (D) & $1.35 \pm 2.140$ & $1.75 \pm 2.333$ & 0.505 \\
\hline Total corneal astigmatism (D) & $0.540 \pm 0.227$ & $0.654 \pm 0.128$ & 0.188 \\
\hline Nuclear sclerosis $\dagger$ & $0.18 \pm 0.669$ & $0.14 \pm 0.525$ & 0.825 \\
\hline Average keratometry (D) & $43.98 \pm 1.430$ & $44.02 \pm 1.595$ & 0.915 \\
\hline Axial length $(\mathrm{mm})$ & $21.87 \pm 1.600$ & $21.75 \pm 1.644$ & 0.776 \\
\hline Anterior chamber depth (mm) & $3.17 \pm 0.218$ & $3.19 \pm 0.255$ & 0.831 \\
\hline
\end{tabular}


(Table 1) contd.....

\begin{tabular}{|c|c|c|}
\hline \multirow{2}{*}{ Parameter } & \multicolumn{2}{|c|}{ Monocular } \\
\cline { 2 - 4 } & \multicolumn{2}{|c|}{ Mean value \pm SD } \\
\cline { 2 - 4 } & FS value & CP \\
\hline White-to-white $(\mathrm{mm})$ & $11.77 \pm 0.293$ & $11.77 \pm 0.289$ \\
\hline
\end{tabular}

CDVA = corrected distance visual acuity $(6 \mathrm{~m}) ; \mathrm{CP}=$ conventional phaco; $\mathrm{D}=$ diopters; LogMAR = logarithm of the minimum angle of resolution; FS = femtosecond; $\mathrm{SD}$

$=$ Standard Deviation; UDVA = uncorrected distance visual acuity $(6 \mathrm{~m})$

$\dagger$ Lens Opacities Classification System III grade

Table 2. Case distribution between the 2 surgeons and between the 2 treatment techniques $(p=0.987)$.*

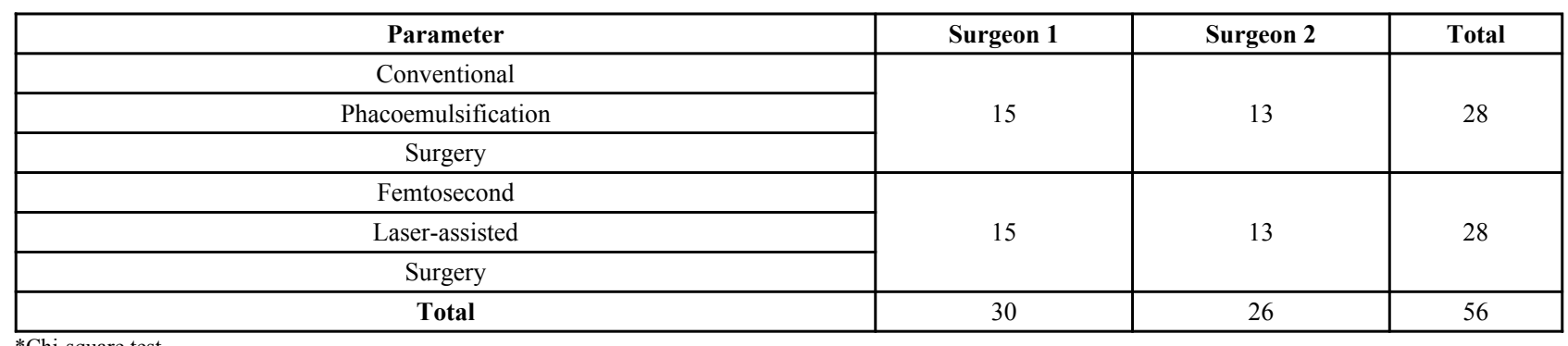

*Chi-square test.

\subsection{Refraction and Visual Acuity}

Femtosecond laser treatment was delivered successfully in all cases in the FS group, with no adverse events registered (including the presence of myosis or significant bubbles); similarly, conventional phacoemulsification was performed without any adverse events.

Mean postop UDVA was $0.01 \pm 0.0661 \log$ MAR (range -0.1 to 0.18 ) for all operated eyes (both techniques), while mean postop CDVA was $-0.01 \pm 0.0412 \log$ MAR (range -0.1 to 0 ). The mean duration of surgical procedures was $14.80 \pm$ $2.733 \mathrm{~min}$ for the femtosecond laser-assisted surgery (FLALS or FS) and $14.69 \pm 2.121 \mathrm{~min}$ for Conventional Phacoemulsification (CP) $(\mathrm{p}>0.05)$.

As shown in Table 3, mean postop visual acuity data did not differ significantly between techniques ( $p$ values $>0.05$ ) at 6 months postoperatively. Cumulative snellen visual acuity is shown in Fig. (1), comparing uncorrected and corrected postoperative values for far, intermediate and near for the two techniques. Twenty-six eyes (92.8\%) in the FS group and 25 eyes $(89.3 \%)$ in the CP group had a monocular UDVA of $20 / 25$ or better; all eyes in both groups had a minimum UDVA of
20/32 at 6 months postoperatively. Twenty-seven eyes (96.4\%), both in FS and CP groups, had a CDVA of at least 20/20, and all eyes in both groups had a CDVA of 20/25 (Fig. 1A).

CDVA $=$ corrected distance visual acuity $(6 \mathrm{~m}) ; \mathrm{D}=$ diopters; DCIVA = distance-corrected intermediate visual acuity $($ at $60 \mathrm{~cm})$; DCNVA = distance-corrected near visual acuity $(40 \mathrm{~cm}) ; \operatorname{LogMAR}=$ logarithm of the minimum angle of resolution; UDVA = uncorrected distance visual acuity $(6 \mathrm{~m})$; UIVA = uncorrected intermediate visual acuity (at $60 \mathrm{~cm})$; UNVA = uncorrected near visual acuity $(40 \mathrm{~cm})$

Regarding postop UIVA, the CP group presented with $20 / 20$ in $85.7 \%$ of the eyes against $78.6 \%$ in the FS group $(\mathrm{p}=0.494)$, with closer results for DCIVA of $20 / 20(78.6 \% \mathrm{vs}$ $75 \%$, respectively for $\mathrm{CP}$ and $\mathrm{FS})(\mathrm{p}=0.955)$ (Fig. 1B). Concerning UNVA and DCNVA, mean values did not differ significantly $(\mathrm{p}=0.803$ and $\mathrm{p}=0.968$, respectively); for DCNVA, $92.8 \%$ in the FS group and $85.7 \%$ in the CP group achieved $20 / 25$ or better (Fig. 1C). Considering safety in the context of the best measured visual acuity, histograms for far, intermediate and near are shown in Fig. (2), with similar results for both techniques.

Table 3. Postoperative visual and refractive outcomes.

\begin{tabular}{|c|c|c|c|}
\hline \multirow{3}{*}{ Parameter } & \multicolumn{3}{|c|}{ Monocular } \\
\hline & \multicolumn{2}{|c|}{ Mean value \pm SD } & \multirow{2}{*}{ Pvalue } \\
\hline & FS & $\mathbf{C P}$ & \\
\hline UDVA (LogMAR) & $0.01 \pm 0.068$ & $0.02 \pm 0.065$ & 0.337 \\
\hline CDVA (LogMAR) & $-0.01 \pm 0.044$ & $-0.01 \pm 0.038$ & 0.522 \\
\hline UIVA (LogMAR) & $0.02 \pm 0.042$ & $0.01 \pm 0.036$ & 0.494 \\
\hline DCIVA (LogMAR) & $0.03 \pm 0.044$ & $0.02 \pm 0.049$ & 0.955 \\
\hline UNVA (LogMAR) & $0.04 \pm 0.054$ & $0.04 \pm 0.059$ & 0.851 \\
\hline DCNVA (LogMAR) & $0.05 \pm 0.060$ & $0.04 \pm 0.070$ & 0.968 \\
\hline Spherical Equivalent (D) & $0.009 \pm 0.259$ & $-0.054 \pm 0.574$ & 0.575 \\
\hline
\end{tabular}

CDVA = corrected distance visual acuity $(6 \mathrm{~m})$; $\mathrm{D}=$ diopters; DCIVA = distance-corrected intermediate visual acuity $($ at $60 \mathrm{~cm})$; DCNVA = distance-corrected near visual acuity $(40 \mathrm{~cm}) ; \operatorname{LogMAR}=$ logarithm of the minimum angle of resolution; UDVA $=$ uncorrected distance visual acuity $(6 \mathrm{~m})$; UIVA = uncorrected intermediate visual acuity $($ at $60 \mathrm{~cm})$; UNVA = uncorrected near visual acuity $(40 \mathrm{~cm})$. 


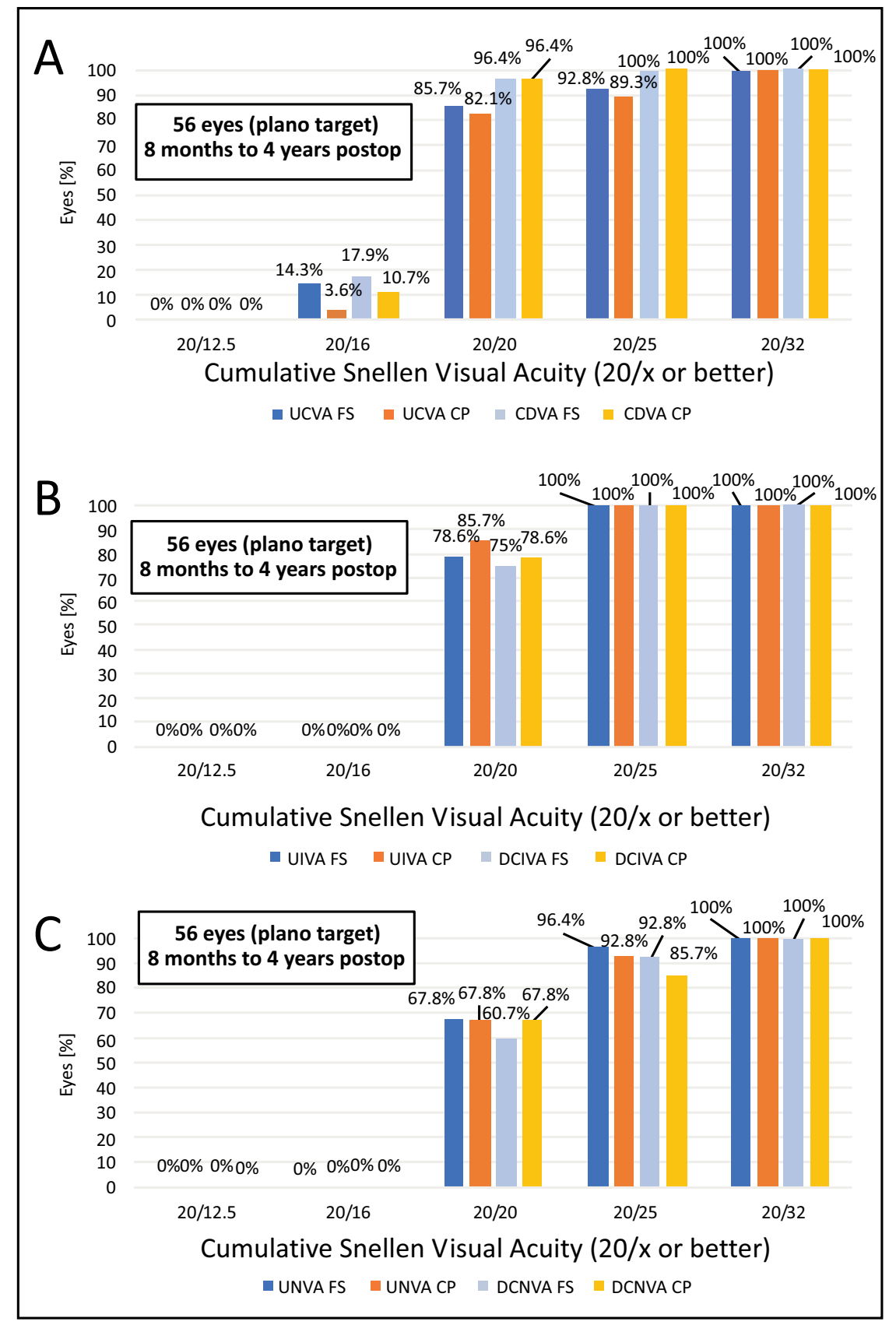

Fig. (1). (A, B and C) Cumulative postoperative monocular visual acuity at last visit (28 eyes in each group) $(\mathrm{CDVA}=\mathrm{corrected}$ distance visual acuity $(6 \mathrm{~m}) ; \mathrm{CP}=$ conventional phacoemulsification group; DCIVA $=$ distance-corrected intermediate visual acuity $($ at $60 \mathrm{~cm})$; DCNVA $=$ distancecorrected near visual acuity $(40 \mathrm{~cm}) ; \mathrm{FS}=$ femtosecond group; UDVA = uncorrected distance visual acuity $(6 \mathrm{~m})$; UIVA = uncorrected intermediate visual acuity (at $60 \mathrm{~cm}) ; \mathrm{UNVA}=$ uncorrected near visual acuity $(40 \mathrm{~cm})$.

The assessment of efficacy and safety outcomes from an essentially refractive point of view (comparing preop CDVA vs. postop UDVA and CDVA, respectively) is also shown in the histograms in Fig. (3). The efficacy index was high for both techniques, with $1.08 \pm 0.149$ for the FS group and $1.05 \pm$
0.244 for the CP group ( $\mathrm{p}=0.893)$. With regard to the safety index, the FS group of eyes achieved a value of $1.13 \pm 0.244$, whereas the CP group had a similar value of $1.12 \pm 0.236$ $(p=0.888)$. Regarding efficacy and safety indexes, there was no clinical difference between the techniques $(p>0.5)$. 


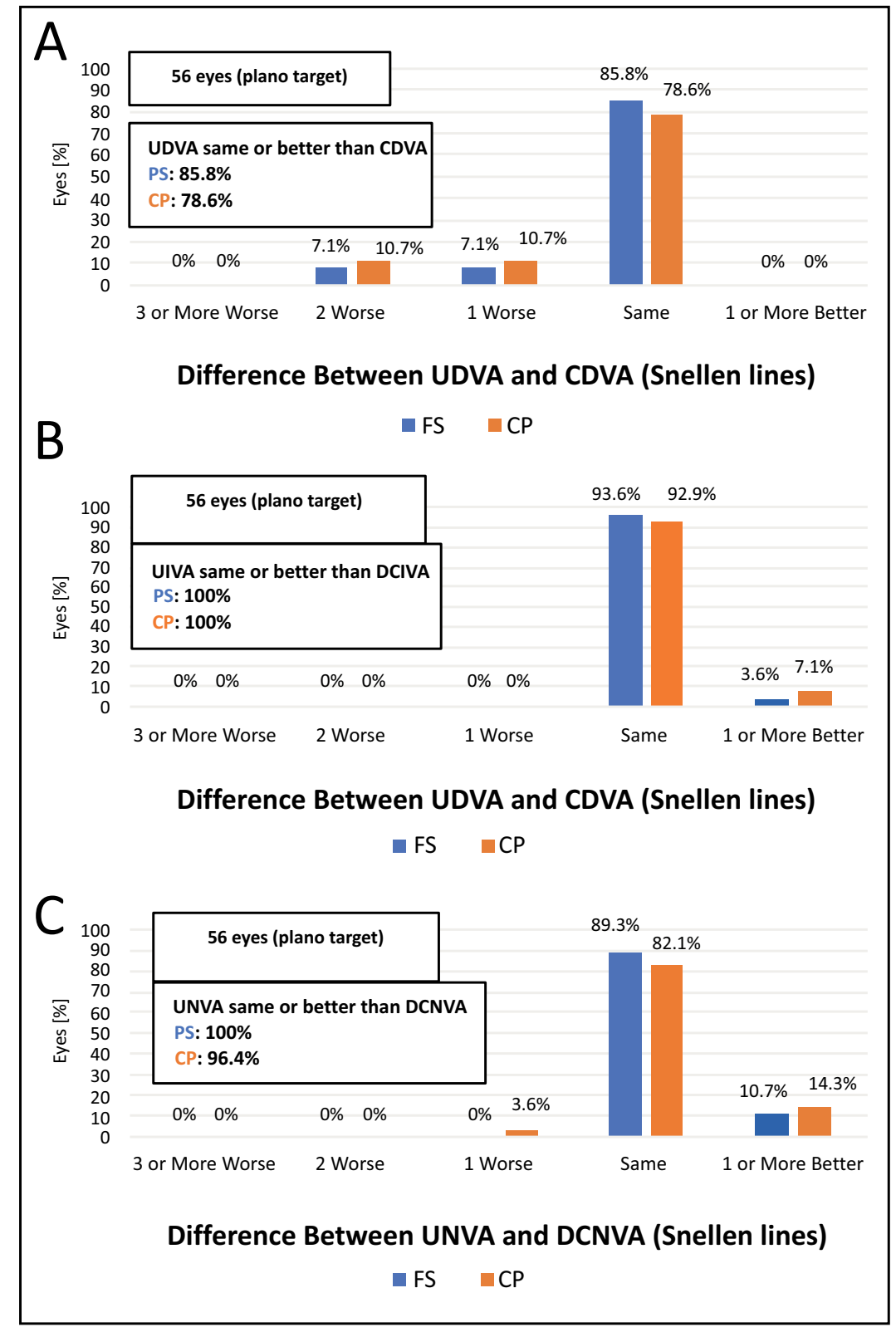

Fig. (2). (A, B and C) Difference between postoperative uncorrected and corrected monocular visual acuity at last visit (28 eyes in each group) (CDVA = corrected distance visual acuity $(6 \mathrm{~m}) ; \mathrm{CP}=$ conventional phacoemulsification group; DCIVA = distance-corrected intermediate visual acuity $(60 \mathrm{~cm}) ; \mathrm{DCNVA}=$ distance-corrected near visual acuity $(40 \mathrm{~cm}) ; \mathrm{FS}=$ femtosecond group; UDVA = uncorrected distance visual acuity $(6 \mathrm{~m})$; $\mathrm{UIVA}=$ uncorrected intermediate visual acuity $($ at $60 \mathrm{~cm}) ; \mathrm{UNVA}=$ uncorrected near visual acuity $(40 \mathrm{~cm})$.

The accuracy of both techniques, regarding postoperative spherical equivalent, is shown in Fig. (4A). In the FS group, $96.4 \%$ of the eyes fell in $\pm 0.50 \mathrm{D}$ range, compared to $84 \%$ of the eyes in the CP group. Four eyes $(14.2 \%)$ in the CP presented with a negative postoperative spherical equivalent in the range of -0.51 to $-1.25 \mathrm{D}$. Postoperative refractive cylinder assessment showed no differences between the two groups (Fig. 4B). Evaluation of the achieved versus attempted spherical equivalent refraction was conducted (Fig. 4C and D), with regression analysis showing the determination coefficients for both groups; the value of $\mathrm{R}^{2}$ was similar for the FS group $\left(\mathrm{R}^{2}=0.9859\right)$ and $\mathrm{CP}$ group $\left(\mathrm{R}^{2}=0.9687\right)$, thus not validating lower predictability of the CP procedure as compared to FS technique for this study population.

Stability of refraction was defined as a change of manifest refraction inferior to $0.5 \mathrm{D}$ between the $1^{\text {st }}$ month visit and the last visit. Refraction was stable in all FS eyes, whereas a change occurred in 2 of the 28 eyes (7.1\%) operated with CP between $1^{\text {st }}$ month and $6^{\text {th }}$ month visits (Fig. 5). There was a myopic change of $0.50 \mathrm{D}$ towards "plano" $(0.0 \mathrm{D})$ refraction. 


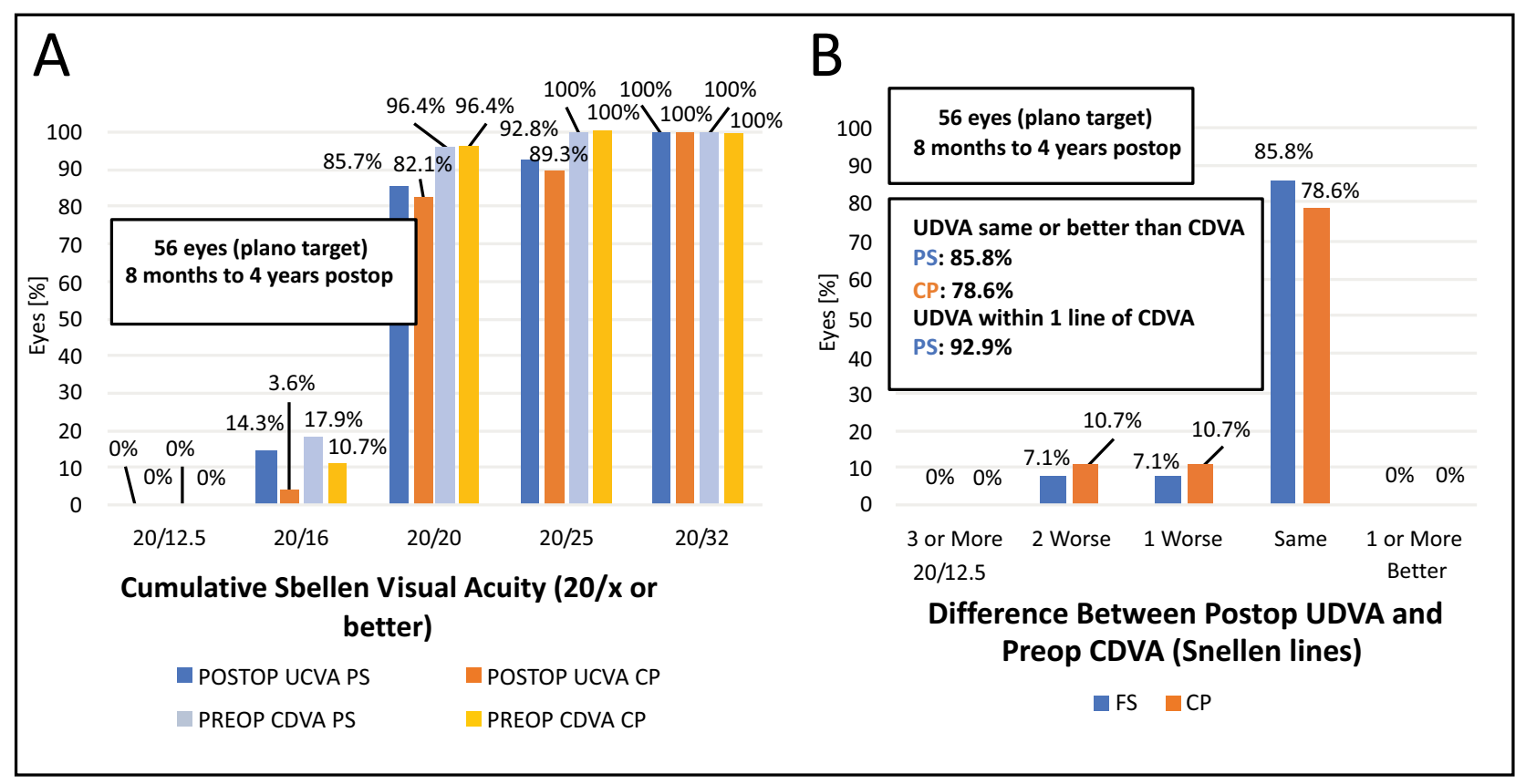

Fig. (3). (A) Cumulative monocular postop UDVA vs. preop CDVA at last visit (28 eyes in each group). (B) Difference between postop monocular CDVA and preop CDVA at last visit (28 eyes in each group) (CDVA = corrected distance visual acuity; $\mathrm{FS}=\mathrm{femtosecond}$ group; $\mathrm{CP}=\mathrm{conventional}$ phacoemulsification group; UDVA = uncorrected distance visual acuity).

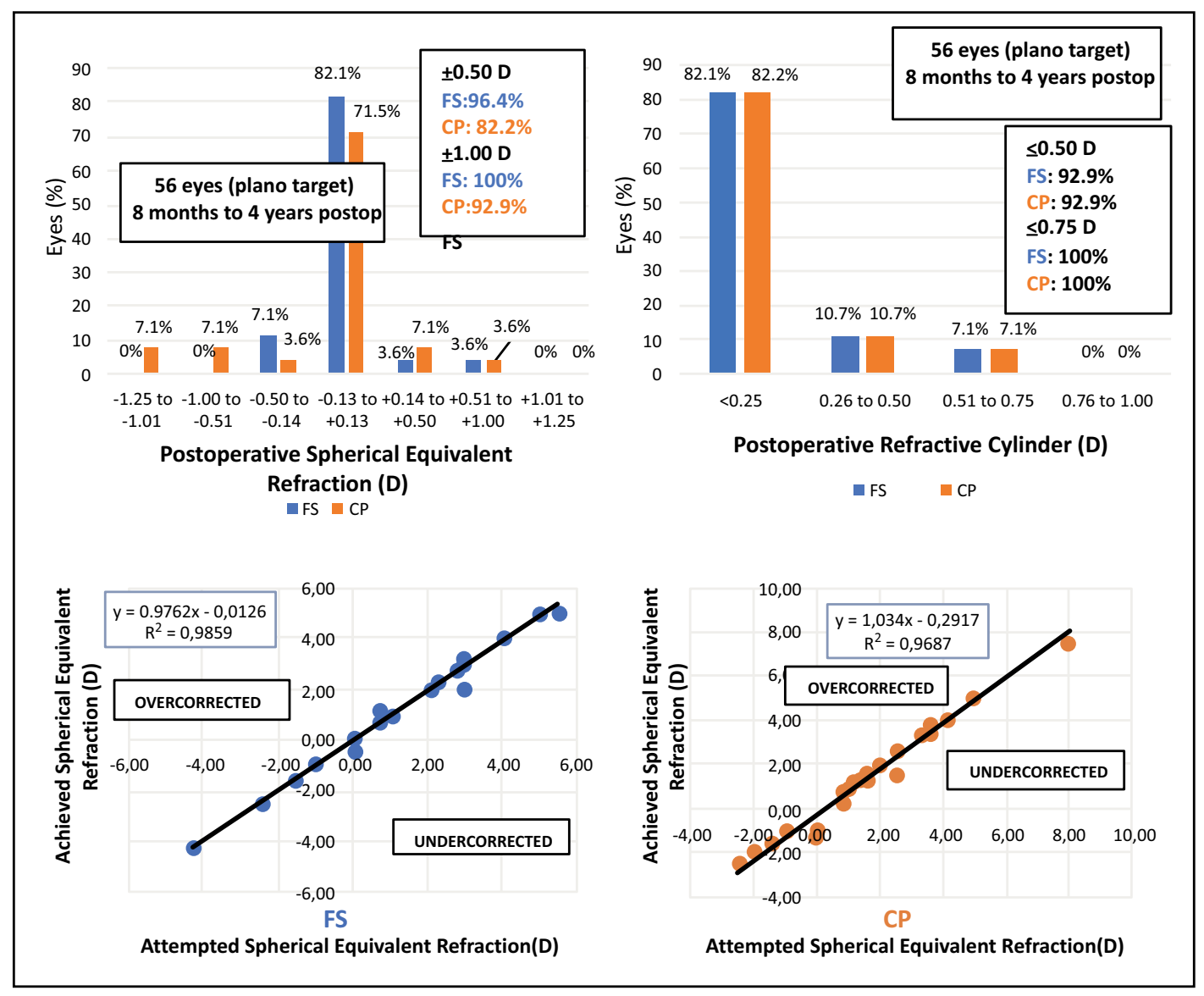

Fig. (4). (A) Accuracy of postoperative refractive spherical equivalent ( $\mathrm{n}=28$ eyes in each group). (B) Postoperative Refractive Cylinder (D). (C and D) Achieved versus Attempted Spherical Equivalent Refraction ( $\mathrm{CP}=$ conventional phacoemulsification group; $\mathrm{D}=$ diopters; FS $=$ femtosecond group). 


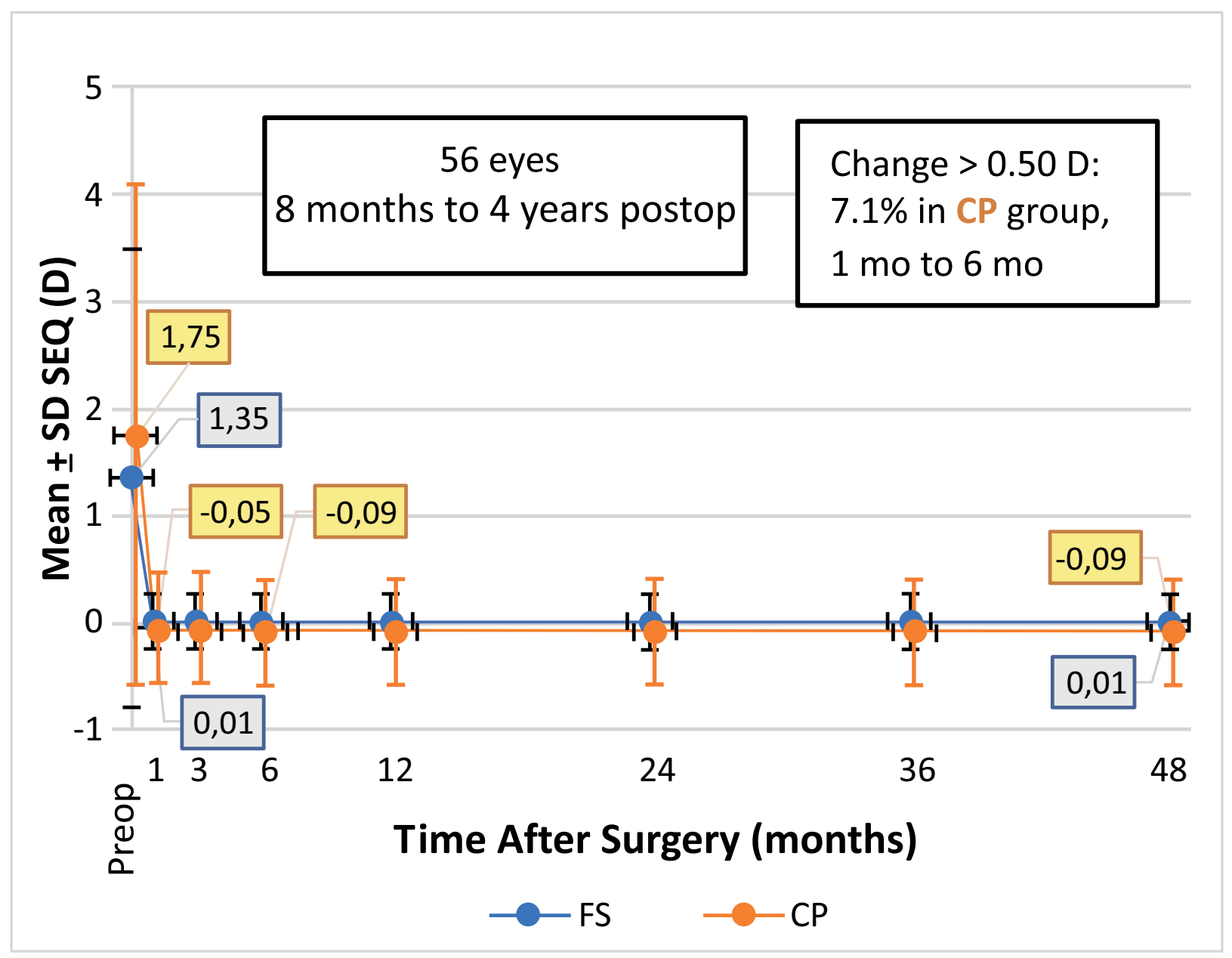

Fig. (5). Stability of spherical equivalent refraction ( $\mathrm{CP}=$ conventional phacoemulsification group; $\mathrm{D}=$ diopters; FS = femtosecond group).

Table 4. Postoperative visual and refractive outcomes.

\begin{tabular}{|c|c|c|c|}
\hline \multirow{2}{*}{ Parameter } & \multicolumn{3}{|c|}{ Monocular } \\
\cline { 2 - 4 } & FS & CP & p value \\
\hline QoV & $1.14 \pm 0.650$ & $1.29 \pm 0.713$ & 0.103 \\
\hline Satisfaction Index & $4.54 \pm 0.508$ & $4.34 \pm 0.488$ & 0.134 \\
\hline
\end{tabular}

No statistically significant difference between the two techniques was obtained regarding refraction assessment, in spite of a difference between techniques regarding the accuracy of spherical equivalent (SE), with $96.4 \%$ of eyes in the FS group presenting postoperative manifest refraction in the $\pm 0.50 \mathrm{D}$ range, as compared to $84 \%$ of the $\mathrm{CP}$ group eyes. At 6 months' timepoint, we found no significant difference in the postoperative visual acuity or postoperative spherical equivalent between the two groups.

Quality of vision and satisfaction, assessed at 6 months' visit, were slightly better with FLALS, but still not statistically significant ( $\mathrm{p}=0.103$ and $\mathrm{p}=0.134$, respectively) (Table 4).

\section{DISCUSSION}

To this point, no other study involving presbyopia correction has assessed the visual outcomes intra-individually with this follow-up line of time (4 years). In the current study, we chose to evaluate patients' charts at 4 weeks and beyond when the majority of postoperative oedema and inflammation had settled. At the 6 months' timepoint, we found no difference in the postoperative visual acuity between the two groups, with no changes thereafter in subsequent visits. The stability of refraction for both techniques was high, notwithstanding the registered changes in the $\mathrm{CP}$ group and pointing to some earlier stabilization of refraction in the FS group, thereby being in agreement with other studies $[18,19]$.

The high values of efficacy and safety indexes in both groups enlighten the good performance of the PanOptix IOL in what concerns to distance visual acuity, being in line with previously reported results $[20,21]$. On the basis of techniques' comparison, a small, clinically non-significant superiority of FS over CP has been reported in terms of efficacy, safety and 
accuracy, as also stated in some studies [22], but further investigation and discussion are required as our study sample was relatively small.

Globally, our results tend to agree with most of the published studies pointing to the similarity of clinical outcomes between femtosecond laser-assisted cataract surgery treatment and CP [23 - 25]. Reported gains in visual acuity after femtosecond laser-assisted surgery, in most studies [26], tend to be early ( 1 week postoperatively) or late (at 6 months), but not between the 1- to 3-month timepoints [27]. The rationale for this might be that femtosecond laser-assisted cataract surgery, in the early postoperative phase, is associated with reduced ultrasound energy and reduced corneal edema resulting in faster visual rehabilitation, followed by equivalence in the interim, and possibly, with late differences after 6 months, as some studies also suggest [28 - 30]. In our study, refraction was stable in all FS eyes, whereas a change occurred in 2 of the 28 eyes (7.1\%) operated with CP between 1 st month and 6th month visits, but without statistical significance $(\mathrm{p}>0.05)$.

It should be stressed, however, that the vast majority of the published evidence does not include nor differentiate the results obtained with each femtosecond delivery machine (namely both types of femtosecond pulse), neither at the visual outcomes nor at the adverse events level. In our study, no adverse events, including myosis after femtosecond delivery, were registered; regarding myosis, our results are in accordance with other studies involving the same type of femtosecond pulse [31]. We did not find the commonly reported reflective pupil constriction associated with other types (high-energy and low-frequency) of femtosecond pulse as it is delivered by most FS machines available in the market. A possible explanation for this difference may be that the "lowenergy" concept (employing a high numerical aperture in the femtosecond laser optics) produces smaller laser spots, which is liable to reduce collateral damage to the neighbouring tissues. This, in turn, could result in lower amounts of prostaglandins with consequent negligible (if any) intraoperative pupil narrowing. Furthermore, the time expended in patient transfer, required for most "high-energy" pulse platforms, may account for the loss of previously pharmacological induced mydriasis. Similarly, in our study, no anterior or posterior capsule-related events were registered, such as incomplete capsulotomy, anterior capsular tags and anterior or posterior capsular tears, contrary to reports of several reviews $[32,33]$, which do not contemplate and/or differentiate between the two types of femtosecond pulse.

Regarding total procedure time (from first to final surgical step), we found no clinically significant difference between FLALS and CP $(p>0.05)$ in our study, with no expended extra time, mostly due to the fact that the employed femtosecond device is portable and it was used in the operating room, with the patient positioned in the surgical bed throughout the sequential femto-phaco procedure. These findings of none or little impact on total surgical time with portable femtosecond device are in agreement with few other studies [34]. Although some studies show a marginal gain in productivity with FLACS [35], the great majority of previous literature indicates a negative impact on productivity by incorporating a femtosecond laser; this evidence can largely be attributed to transfer time between the laser and the surgical bed or between laser and operating room, since, for these studies, only nonportable femtosecond devices have been included [36 - 38].

\section{CONCLUSION}

The vast majority of the studies exclude femtosecond lasers of low-energy and high-frequency pulse in lens surgery. To our knowledge, until this date, this is the only intraindividual study evaluating low-energy and highfrequency femtosecond pulse in lens surgery for presbyopia correction, and also for a 1 to 4 years of follow-up period. Most of the several studies showed little overall differences in visual and refractive outcomes between femtosecond laser-assisted cataract surgery and $\mathrm{CP}$, along with productivity concerns (time expenditure) generally associated with the use of femtosecond laser in lens surgery, which have been observed to be comparatively worse in conventional phacoemulsification. In the present study, total procedure time was similar between the techniques, and no adverse events were registered, including post-femtosecond delivery myosis. Altogether, there was no significant difference registered between the techniques regarding clinical outcomes. Stability, although not statistically significant, was slightly better with FLACS. The present study is limited with respect to the number of participants. As such, a larger sample size is recommended to confirm and investigate these findings further.

\section{ETHICS APPROVAL AND CONSENT TO PARTI- CIPATE}

This retrospective cohort study was approved by the Ethics Committee at Hospital da Luz Arrabida (HLA), Porto, Portugal.

\section{HUMAN AND ANIMAL RIGHTS}

No animals were used in this research. All human research procedures followed were in accordance with the ethical standards of the committee responsible for human experimentation (institutional and national), and with the Helsinki Declaration of 1975, as revised in 2013.

\section{CONSENT FOR PUBLICATION}

Informed consent was obtained from the participants to ensure the confidentiality and anonymity of the study.

\section{AVAILABILITY OF DATA AND MATERIALS}

Not applicable.

\section{FUNDING}

None.

\section{CONFLICT OF INTEREST}

The authors declare no conflict of interest, financial or otherwise. 


\section{ACKNOWLEDGEMENTS}

Pedro Oliveira, $\mathrm{PhD}$, University of Porto, provided assistance with statistics.

Ramiro Salgado, Antonio Marinho and Paulo Torres planned the study. Ramiro Salgado and Antonio Marinho conducted the study. Ramiro Salgado submitted the study and is responsible for the overall content as guarantor.

\section{REFERENCES}

[1] Yamauchi T, Tabuchi H, Takase K, Ohsugi H, Ohara Z, Kiuchi Y. Comparison of visual performance of multifocal intraocular lenses with same material monofocal intraocular lenses. PLoS One 2013; $8(6) \mathrm{e} 68236$

[http://dx.doi.org/10.1371/journal.pone.0068236] [PMID: 23840836]

[2] Salerno LC, Tiveron MC Jr, Alió JL. Multifocal intraocular lenses: Types, outcomes, complications and how to solve them. Taiwan J Ophthalmol 2017; 7(4): 179-84.

[http://dx.doi.org/10.4103/tjo.tjo_19_17] [PMID: 29296549]

[3] Nagy Z, Takacs A, Filkorn T, Sarayba M. Initial clinical evaluation of an intraocular femtosecond laser in cataract surgery. J Refract Surg 2009; 25(12): 1053-60.

[http://dx.doi.org/10.3928/1081597X-20091117-04] [PMID: 20000286]

[4] Mastropasqua L, Toto L, Mattei PA, et al. Optical coherence tomography and 3-dimensional confocal structured imaging systemguided femtosecond laser capsulotomy versus manual continuous curvilinear capsulorhexis. J Cataract Refract Surg 2014; 40(12): 2035-43.

[http://dx.doi.org/10.1016/j.jcrs.2014.05.032] [PMID: 25450242]

[5] Mastropasqua L, Toto L, Mastropasqua A, et al. Femtosecond laser versus manual clear corneal incision in cataract surgery. J Refract Surg 2014; 30(1): 27-33.

[http://dx.doi.org/10.3928/1081597X-20131217-03] [PMID: 24864325]

[6] Reddy KP, Kandulla J, Auffarth GU. Effectiveness and safety of femtosecond laser-assisted lens fragmentation and anterior capsulotomy versus the manual technique in cataract surgery. J Cataract Refract Surg 2013; 39(9): 1297-306. [http://dx.doi.org/10.1016/j.jcrs.2013.05.035] [PMID: 23988242]

[7] Toto L, Mastropasqua R, Mattei PA, et al. Postoperative IOL axial movements and refractive changes after femtosecond laser-assisted cataract surgery versus conventional phacoemulsification. J Refract Surg 2015; 31(8): 524-30.

[http://dx.doi.org/10.3928/1081597X-20150727-02] [PMID: 26248345]

[8] Kránitz K, Miháltz K, Sándor GL, Takacs A, Knorz MC, Nagy ZZ. Intraocular lens tilt and decentration measured by scheimpflug camera following manual or femtosecond laser-created continuous circular capsulotomy. J Refract Surg 2012; 28(4): 259-63. [http://dx.doi.org/10.3928/1081597X-20120309-01] [PMID: 22496437]

[9] Turuwhenua J. A theoretical study of intraocular lens tilt and decentration on perceptual image quality. Ophthalmic Physiol Opt 2005; 25(6): 556-67.

[http://dx.doi.org/10.1111/j.1475-1313.2005.00314.x] [PMID: 16343131]

[10] Oshika T, Kawana K, Hiraoka T, Kaji Y, Kiuchi T. Ocular higherorder wavefront aberration caused by major tilting of intraocular lens. Am J Ophthalmol 2005; 140(4): 744-6.

[http://dx.doi.org/10.1016/j.ajo.2005.04.026] [PMID: 16226535]

[11] Altmann GE, Nichamin LD, Lane SS, Pepose JS. Optical performance of 3 intraocular lens designs in the presence of decentration. J Cataract Refract Surg 2005; 31(3): 574-85.

[http://dx.doi.org/10.1016/j.jcrs.2004.09.024] [PMID: 15811748]

[12] Lee JA, Song WK, Kim JY, Kim MJ, Tchah H. Femtosecond laserassisted cataract surgery versus conventional phacoemulsification: Refractive and aberrometric outcomes with a diffractive multifocal intraocular lens. J Cataract Refract Surg 2019; 45(1): 21-7.

[http://dx.doi.org/10.1016/j.jcrs.2018.08.032] [PMID: 30424904]

[13] Wu BM, Williams GP, Tan A, Mehta JS. A comparison of different operating systems for femtosecond lasers in cataract surgery. J Ophthalmol 2015; 2015616478

[http://dx.doi.org/10.1155/2015/616478] [PMID: 26483973]
[14] Yoo A, Kwag JY, Song IS, et al. Comparison of visual function after implantation of inferior sector-shaped intraocular lenses: low-add +1.5 D vs +3.0 D. Eur J Ophthalmol 2016; 26(6): 607-11.

[http://dx.doi.org/10.5301/ejo.5000771] [PMID: 27646332]

[15] Kohnen T, Herzog M, Hemkeppler E, et al. Visual performance of a quadrifocal (trifocal) lens following removal of the crystalline lens. Am J Ophthalmol 2017; 184: 52-62.

[http://dx.doi.org/10.1016/j.ajo.2017.09.016] [PMID: 28923587]

[16] Lee S, Choi M, Xu Z, Zhao Z, Alexander E, Liu Y. Optical bench performance of a novel trifocal intraocular lens compared with a multifocal intraocular lens. Clin Ophthalmol 2016; 10: 1031-8. [http://dx.doi.org/10.2147/OPTH.S106646] [PMID: 27330273]

[17] Carson D, Hill WE, Hong X, Karakelle M. Optical bench performance of AcrySof $(\circledR)$ IQ ReSTOR $(\circledR)$, AT LISA $\left({ }^{\circledR}\right)$ tri, and FineVision $(\circledR)$ intraocular lenses. Clin Ophthalmol 2014; 8: 2105-13. [PMID: 25342881]

[18] Ye Z, Li Z, He S. A meta-analysis comparing postoperative complications and outcomes of femtosecond laser-assisted cataract surgery versus conventional phacoemulsification for cataract. J Ophthalmol 2017; 20173849152

[http://dx.doi.org/10.1155/2017/3849152] [PMID: 28540082]

[19] Chen X, Xiao W, Ye S, Chen W, Liu Y. Efficacy and safety of femtosecond laser-assisted cataract surgery versus conventional phacoemulsification for cataract: A meta-analysis of randomized controlled trials. Sci Rep 2015; 5: 13123.

[http://dx.doi.org/10.1038/srep13123] [PMID: 26269445]

[20] Rementería-Capelo LA, Contreras I, García-Pérez JL, Blázquez V, Ruiz-Alcocer J. Visual quality and patient satisfaction with a trifocal intraocular lens and its new toric version. J Cataract Refract Surg 2019; 45(11): 1584-90.

[http://dx.doi.org/10.1016/j.jcrs.2019.06.014] [PMID: 31587937]

[21] Böhm M, Petermann K, Hemkeppler E, Kohnen T. Defocus curves of 4 presbyopia-correcting IOL designs: Diffractive panfocal, diffractive trifocal, segmental refractive, and extended-depth-of-focus. J Cataract Refract Surg 2019; 45(11): 1625-36.

[http://dx.doi.org/10.1016/j.jcrs.2019.07.014] [PMID: 31706517]

[22] Shaheen MS, AbouSamra A, Helaly HA, Said A, Elmassry A Comparison between refractive outcomes of femtosecond laserassisted cataract surgery and standard phacoemulsification. BMC Ophthalmol 2020; 20(1): 1.

[http://dx.doi.org/10.1186/s12886-019-1277-9] [PMID: 31898534]

[23] Day AC, Gore DM, Bunce C. Laser assisted versus manual phacoemulsification for lens extraction. Cochrane Database Syst Rev 2013; 9CD010735

[http://dx.doi.org/10.1002/14651858.CD010735]

[24] Manning S, Barry P, Henry Y, et al. Femtosecond laser-assisted cataract surgery versus standard phacoemulsification cataract surgery: Study from the european registry of quality outcomes for cataract and refractive Surgery. J Cataract Refract Surg 2016; 42(12): 1779-90. [http://dx.doi.org/10.1016/j.jcrs.2016.10.013] [PMID: 28007110]

[25] Abell RG, Darian-Smith E, Kan JB, Allen PL, Ewe SYP, Vote BJ. Femtosecond laser-assisted cataract surgery versus standard phacoemulsification cataract surgery: Outcomes and safety in more than 4000 cases at a single center. J Cataract Refract Surg 2015; 41(1): 47-52.

[http://dx.doi.org/10.1016/j.jcrs.2014.06.025] [PMID: 25466483]

[26] Conrad-Hengerer I, Al Sheikh M, Hengerer FH, Schultz T, Dick HB. Comparison of visual recovery and refractive stability between femtosecond laser-assisted cataract surgery and standard phacoemulsification: six-month follow-up. J Cataract Refract Surg 2015; 41(7): 1356-64.

[http://dx.doi.org/10.1016/j.jcrs.2014.10.044] [PMID: 26287876]

[27] Roberts HW, Wagh VK, Sullivan DL, et al. A randomized controlled trial comparing femtosecond laser-assisted cataract surgery versus conventional phacoemulsification surgery. J Cataract Refract Surg 2019; 45(1): 11-20.

[http://dx.doi.org/10.1016/j.jcrs.2018.08.033] [PMID: 30413333]

[28] Okada M, Hersh D, Paul E, van der Straaten D. Effect of centration and circularity of manual capsulorrhexis on cataract surgery refractive outcomes. Ophthalmology 2014; 121(3): 763-70.

[http://dx.doi.org/10.1016/j.ophtha.2013.09.049] [PMID: 24342022]

[29] Kovács I, Kránitz K, Sándor GL, et al. The effect of femtosecond laser capsulotomy on the development of posterior capsule opacification. J Refract Surg 2014; 30(3): 154-8.

[http://dx.doi.org/10.3928/1081597X-20140217-01] 24763719]

[30] Yu AY, Ni LY, Wang QM, et al. Preliminary clinical investigation of 
cataract surgery with a noncontact femtosecond laser system. Lasers Surg Med 2015; 47(9): 698-703.

[http://dx.doi.org/10.1002/lsm.22405] [PMID: 26311629]

[31] Mirshahi A, A Ponto K. Changes in pupil area during low-energy femtosecond laser-assisted cataract surgery. J Ophthalmic Vis Res 2019; 14(3): 251-6.

[http://dx.doi.org/10.18502/jovr.v14i3.4780] [PMID: 31660103]

[32] Wang J, Su F, Wang Y, Chen Y, Chen Q, Li F. Intra and postoperative complications observed with femtosecond laser-assisted cataract surgery versus conventional phacoemulsification surgery: a systematic review and meta-analysis. BMC Ophthalmol 2019; 19(1): 177.

[http://dx.doi.org/10.1186/s12886-019-1190-2] [PMID: 31399070]

[33] Popovic M, Campos-Möller X, Schlenker MB, Ahmed II. Efficacy and safety of femtosecond laser-assisted cataract surgery compared with manual cataract surgery: A meta-analysis of 14567 eyes. Ophthalmology 2016; 123(10): 2113-26.

[http://dx.doi.org/10.1016/j.ophtha.2016.07.005] [PMID: 27538796]

[34] Vasquez-Perez A, Simpson A, Nanavaty MA. Femtosecond laserassisted cataract surgery in a public teaching hospital setting. BMC
Ophthalmol 2018; 18(1): 26.

[http://dx.doi.org/10.1186/s12886-018-0693-6] [PMID: 29394929]

[35] Roberts HW, Wagh VK, Mullens IJM, Borsci S, Ni MZ, O’Brart DPS Evaluation of a hub-and-spoke model for the delivery of femtosecond laser-assisted cataract surgery within the context of a large randomised controlled trial. Br J Ophthalmol 2018; 102(11): 1556-63.

[http://dx.doi.org/10.1136/bjophthalmol-2017-311319] [PMID 29436401]

[36] Bali SJ, Hodge C, Lawless M, Roberts TV, Sutton G. Early experience with the femtosecond laser for cataract surgery. Ophthalmology 2012; 119(5): 891-9.

[http://dx.doi.org/10.1016/j.ophtha.2011.12.025] [PMID: 22361311]

[37] Abell RG, Vote BJ. Cost-effectiveness of femtosecond laser-assisted cataract surgery versus phacoemulsification cataract surgery. Ophthalmology 2014; 121(1): 10-6.

[http://dx.doi.org/10.1016/j.ophtha.2013.07.056] [PMID: 24120324]

[38] Lubahn JG, Donaldson KE, Culbertson WW, Yoo SH. Operating times of experienced cataract surgeons beginning femtosecond laserassisted cataract surgery. J Cataract Refract Surg 2014; 40(11): 1773-6.

[http://dx.doi.org/10.1016/j.jcrs.2014.03.024] [PMID: 25217069]

\section{(C) 2021 Salgado et al.}

This is an open access article distributed under the terms of the Creative Commons Attribution 4.0 International Public License (CC-BY 4.0), a copy of which is available at: https://creativecommons.org/licenses/by/4.0/legalcode. This license permits unrestricted use, distribution, and reproduction in any medium, provided the original author and source are credited. 